\title{
Mechanisms of streptozotocin- and alloxan-induced damage in rat B cells
}

\author{
G. L. Wilson ${ }^{1}$, N.J.Patton 1 , J.M. McCord ${ }^{1}$, D. W. Mullins ${ }^{2}$ and B.T.Mossman ${ }^{3}$ \\ ${ }^{1}$ Departments of Anatomy and Biochemistry, University of South Alabama, Mobile, ${ }^{2}$ Department of Biochemistry, University of Alabama \\ in Birmingham, Birmingham, Alabama and ${ }^{3}$ Department of Pathology, University of Vermont, Burlington, Vermont, USA
}

\begin{abstract}
Summary. In studies to evaluate possible inhibitors of the Bcell toxin, streptozotocin, the superoxide scavenger, superoxide dismutase, did not prevent or reduce the toxic effects of streptozotocin as determined by loss of insulin secretion from rat pancreatic $B$ cells in monolayer culture. However, 1,1-dimethyl urea, a scavenger of the hydroxyl radical, did afford significant protection. Both scavengers diminished the cytotoxic effects of alloxan. The inhibitors of poly (ADP-ribose) synthetase, 3-aminobenzamide and nicotinamide, also were effective in attenuating alloxan- and streptozotocin-induced B-cell toxicity. Tests of the hydroxyl-scavenging ability of the three streptozotocin antagonists revealed that 3-aminobenzamide, nicotinamide and 1,1-dimethyl urea were effec-
\end{abstract}

tive scavengers of this free radical. Conversely, 1,1-dimethyl urea, although not as potent as 3-aminobenzamide or nicotinamide, was found to inhibit poly (ADP-ribose) synthetase. These data indicate that these chemicals most likely attenuate alloxan-induced toxicity by scavenging the hydroxyl radical and diminish streptozotocin-induced toxicity by inactivation of the poly (ADP-ribose) system.

Key words: Streptozotocin, alloxan, B-cell monolayer culture, oxygen free radicals, poly (ADP-ribose) synthetase, superoxide dismutase, 1,1-dimethyl urea, 3-aminobenzamide, nicotinamide.
When given in sufficient quantities to a variety of laboratory animals, streptozotocin (STZ) or alloxan cause a diabetes-like disease associated with severe B-cell necrosis $[1,2]$. Differing results have been obtained from studies to elucidate the mechanisms of action of these toxins. Numerous reports have established that the initial event in alloxan-induced B-cell damage is the generation of noxious oxygen free radicals [3-7]. Additionally, several studies have suggested that oxygen free radicals also play a role in STZ-induced toxicity. Both the superoxide scavenger, superoxide dismutase $[8,9]$, and the hydroxyl radical scavenger, 1,1-dimethyl urea [10], have been reported to diminish the toxic effects of STZ. However, some investigators have disputed the protective effect of superoxide dismutase [11, 12].

Other mechanistic investigations have suggested that the final step in STZ- and alloxan-induced B-cell damage is the critical depletion of cellular NAD resulting from its catabolism by the nuclear enzyme poly (ADP-ribose) synthetase [12]. This enzyme is activated as part of the process to repair toxin-induced DNA damage. This hypothesis is supported by the observation that both nicotinamide and 3-aminobenzamide inhibit activation of poly (ADP-ribose) synthetase and re- duce the diabetogenic effects of STZ [12] and alloxan $[12,13]$. The exact sequence of events whereby these two toxins interact with B cells to precipitate functional impairments and cell death remains to be elucidated.

The aim of the present study was to evaluate the effects of both scavengers of oxygen free radicals and inhibitors of poly (ADP-ribose) synthetase on STZ- or alloxan-induced B-cell damage in islet cell monolayer cultures derived from the neonatal rat. In addition, studies were performed to determine whether inhibitors of poly (ADP-ribose) synthetase also scavenge oxygen free radicals. Conversely, other experiments were performed to determine whether a free radical scavenger known to diminish STZ- or alloxan-induced B-cell toxicity could inhibit poly (ADP-ribose) synthetase.

\section{Materials and methods}

\section{Pancreatic islet cell cultures}

The procedures used to prepare islet cell monolayer cultures from the pancreases of neonatal rats have been described previously [14, 15]. After an initial 16-h incubation in $60 \mathrm{~mm}$ culture dishes to remove adherent fibroblastoid cells, suspensions of islet cells were plated into 
$16 \mathrm{~mm}$ culture wells ( 24 wells/plate). Twenty-four hours after plating, the monolayers were treated for $48 \mathrm{~h}$ with serum-free, cysteine-free medium to reduce contamination by fibroblastoid cells [14]. Thereafter, islet cells were maintained using Medium 199 (Flow Laboratories, McLean, Virginia, USA) supplemented with $10 \%$ fetal bovine serum, glucose $(16.5 \mathrm{mmol} / \mathrm{l})$ and gentamicin $(50 \mathrm{mg} / \mathrm{l})$. Fresh medium was added at 48 -h intervals, and the spent medium saved for determination of immunoreactive insulin concentration by radioimmunoassay. On day 8 of culture, the toxins and inhibitors were added to the monolayers.

A $1 \mathrm{mmol} / \mathrm{l}$ concentration of STZ (Lot No.1180K, kindly provided by Dr. W. E. Dulin, UpJohn, Kalamazoo, Michigan) or alloxan (Eastman Kodak, Rochester, New York) was prepared in Hanks' balanced salt solution containing copper-zinc superoxide dismutase (prepared by J.M. McC), 1,1-dimethyl urea (Sigma Biochemicals, St. Louis, Missouri), nicotinamide (Sigma) or 3-aminobenzamide (Sig$\mathrm{ma}$ ) in varying concentrations. The STZ or alloxan initially was dissolved in citrate buffer ( $\mathrm{pH} 4.5$ ) before dilution in Hanks' balanced salt solution. After preparation of the toxin-containing solutions, the culture medium was removed and the monolayers washed twice with Hanks' balanced salt solution. Cultures were then exposed to $0.5 \mathrm{ml}$ of the toxins and inhibitors for $1 \mathrm{~h}$ at $37^{\circ} \mathrm{C}$. Control cultures received either the toxins or the inhibitors or the toxin diluent. After $1 \mathrm{~h}$, the Hanks' balanced salt solution containing test chemicals was removed, and the cultures replenished with $0.5 \mathrm{ml}$ of fresh culture medium. Medium was changed at 48-h intervals thereafter, and the spent medium saved for determination of immunoreactive insulin.

\section{Assay for insulin}

Insulin release during each 48 -h period was determined by a back titration method [16], using ${ }^{125}$ I-labelled porcine insulin (Cambridge Medical Diagnostics, Billerica, Massachusetts) diluted with cold porcine insulin (kindly provided by Dr. R. Chance, Eli Lilly, Indianapolis, Indiana) and guinea pig anti-bovine insulin serum (Linco Research, Eureka, Missouri). Purified rat insulin (kindly provided by Dr. R. Chance, Eli Lilly, Indianapolis, Indiana) was used for standards.

\section{Assay for hydroxyl radical scavengers}

The system for generating and detecting the hydroxyl radical was a modification of those described by Klein et al. [17], and by MoCord and Day [18]. A 1-ml volume of the reaction mixture contained the following: xanthine (Sigma) $(40 \mu \mathrm{mol} / \mathrm{l})$ and bovine milk xanthine oxidase (Sigma) $(0.012 \mathrm{U} / \mathrm{ml})$ as the source of superoxide and $\mathrm{H}_{2} \mathrm{O}_{2}$, with $10 \mu \mathrm{mol} / 1 \mathrm{Fe}$-EDTA present to catalyze hydroxyl production. The radicals were trapped via reaction with $10 \mathrm{mmol} / 1$ 1,1-dimethyl urea, giving rise to formaldehyde. After incubation at $37^{\circ} \mathrm{C}$ for $30 \mathrm{~min}$, the reactions were terminated by the addition of $0.5 \mathrm{ml}$ of cold trichloroacetic acid $(17.5 \% \mathrm{w} / \mathrm{v})$. After centrifugation, $1.0 \mathrm{ml}$ of supernatant was assayed for formaldehyde by the fluorimetric method of Steffer and Netter [19]. The abilities of the various compounds to scavenge the hydroxyl radical were determined by adding the compounds at the indicated concentrations to the initial reaction mixtures.

\section{Assay for inactivation of poly (ADP-ribose) synthetase}

The procedures used to determine inhibition of poly (ADP-ribose) synthetase were those previously described by Benjamin and Gill [20]. Briefly, HeLa cells $\left(2-5 \times 10^{6}\right.$ total cells) were centrifuged, washed two times in ice-cold phosphate buffered saline $(0.154 \mathrm{~mol} / \mathrm{l})$ and then resuspended in $1 \mathrm{ml}$ of lysis solution [ $5 \%$ dextran $\mathrm{T}-110,10 \mathrm{mmol} / \mathrm{l}$, $\mathrm{MgCl}_{2}, 0.05 \%$ Triton X-100,30 mol/1 NAD $+0.5 \mathrm{Ci} / \mathrm{ml}{ }^{3} \mathrm{H}-\mathrm{NAD}$ (Amersham, Arlington Heights, Illinois) and $40 \mathrm{mmol} / 1$ Tris, $\mathrm{pH} 8.0$ ]. The lysis solution also contained the inhibitors in various concentrations. After lysis, the suspensions were incubated at room temperature for $30-60 \mathrm{~min}$ with $0.1 \mathrm{ml}$ aliquots removed at timed intervals and added to ice-cold trichloroacetic acid. Radiolabelled product was recovered on GF/C filters (Whatman, Clifton, New Jersey) and the amount of incorporated isotope determined by liquid scintillation spectrometry.

\section{Statistical analysis}

All grouped data are expressed as mean \pm SEM. Data in the toxicity studies were compared using a two-sample Student's t-test in which data from cultures receiving only the toxin were compared with those from cultures receiving toxin and a potential inhibitor. Data from the studies dealing with the inhibition of the enzyme poly (ADPribose) synthetase also were compared using the same two-sample ttest. The counts of labelled poly (ADP-ribose) formed in the presence of poly (ADP-ribose) synthetase alone were compared to the counts of labelled product formed in the presence of the enzyme and the various inhibitors. All two-sample t-tests evaluated a null hypothesis of $\mu 1 \geqslant \mu 2$. Data from the hydroxyl radical assay were analysed by a one-sample Student's t-test to determine if a significant difference existed between the mean of the data and a constant. The data in this experiment are expressed as a percentage decrease in formaldehyde formation. Therefore, the constant is zero since there would not be a decrease in formaldehyde formation if the compound being tested did not scavenge a detectable amount of the hydroxyl radicals. The null hypothesis evaluated for the one-sample $t$-test was $\mu \leqslant 0$. In all cases in which statistical evaluations were performed, $p<0.05$ was considered significant.

\section{Results}

\section{Effects of oxygen free radical scavengers on streptozotocin- and alloxan-induced B-cell injury}

The scavenger of the superoxide radical, superoxide dismutase, did not protect against the toxic effects of STZ at concentrations up to $5000 \mathrm{U} / \mathrm{ml}$ (Fig. 1). However, this scavenger did significantly attenuate alloxaninduced toxicity (Fig.1). The hydroxyl radical scavenger, 1,1-dimethyl urea, significantly reduced the toxic effects of STZ in a dose-dependent manner up to a concentration of $50 \mathrm{mg} / \mathrm{ml}$ (Fig. 2a). This compound also protected against the toxic effects of alloxan in a similar fashion (Fig. 2b).

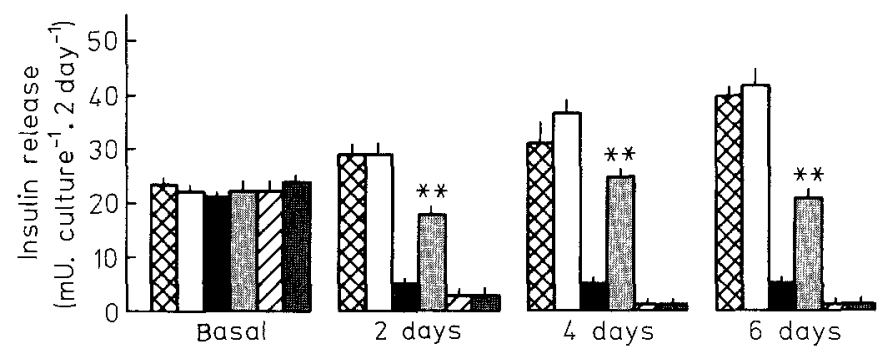

Fig. 1. Insulin release after exposure to streptozotocin and various concentrations of superoxide dismutase for $1 \mathrm{~h}$ with the following additions: $\otimes$ toxin diluent only, $\square 5000 \mathrm{U} / \mathrm{ml}$ superoxide dismutase.

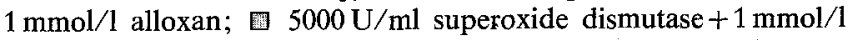
alloxan; $1 \mathrm{mmol} / 1$ streptozotocin; $5000 \mathrm{U} / \mathrm{ml}$ superoxide dismutase $+1 \mathrm{mmol} / 1$ streptozotocin. Data are expressed as the mean \pm SEM of the amount of insulin released by four separate cultures at 2-day intervals before and after exposure to the toxin. Values are from a single experiment representative of three separate experiments. ** denotes $p<0.005$ when tested against toxin in the absence of inhibitors using a two-sample t-test 


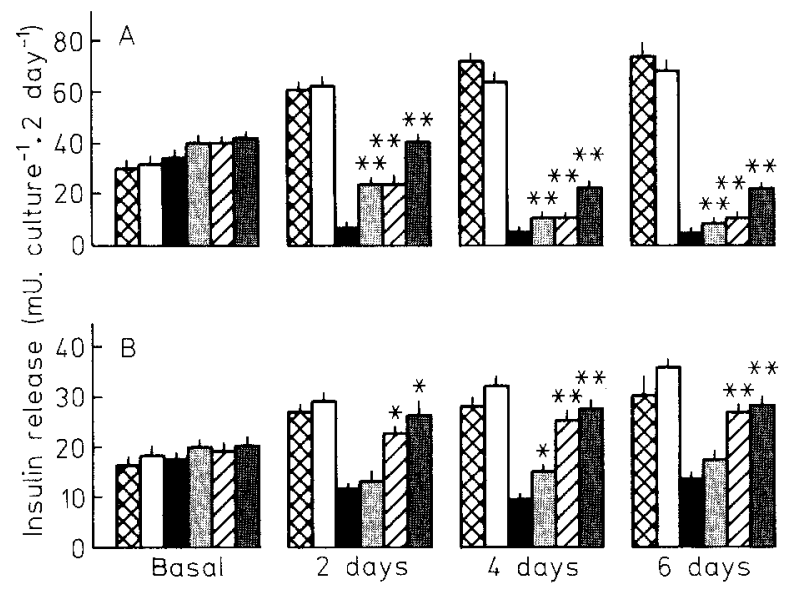

Fig. $2 \mathbf{A}$ and B. Insulin release after exposure to streptozotocin (A) or alloxan (B) and various concentrations of 1,1-dimethyl urea for $1 \mathrm{~h}$, with the following additions. A $\otimes$ streptozotocin diluent only; $\square$ $50 \mathrm{mg} / \mathrm{ml}$ 1,1-dimethyl urea; $1 \mathrm{mmol} / 1$ streptozotocin; $10 \mathrm{mg} /$ $\mathrm{ml}$ 1,1-dimethyl urea $+1 \mathrm{mmol} / 1$ streptozotocin; $20 \mathrm{mg} / \mathrm{ml}$ 1,1-dimethyl urea $+1 \mathrm{mmol} / 1$ streptozotocin; $50 \mathrm{mg} / \mathrm{ml} 1,1$-dimethyl urea $+1 \mathrm{mmol} / 1$ streptozotocin. $\mathbf{B} \otimes$ alloxan diluent only; $\square$ $50 \mathrm{mg} / \mathrm{ml} \mathrm{1,1-dimethyl} \mathrm{urea;} 1 \mathrm{mmol} / \mathrm{l}$ alloxan; $10 \mathrm{mg} / \mathrm{ml}$ 1,1-dimethyl urea $+1 \mathrm{mmol} / 1$ alloxan; $20 \mathrm{mg} / \mathrm{ml}$ 1,1-dimethyl urea $+1 \mathrm{mmol} / 1$ alloxan; $50 \mathrm{mg} / \mathrm{ml} 1,1$-dimethyl urea $+1 \mathrm{mmol} / 1$ alloxan. Data are expressed on the same basis as described for Figure 1. * and ** denote $p<0.05$ and $p<0.005$ respectively when tested against toxin in the absence of inhibitors using a two-sample t-test

Table 1. Comparison of the hydroxyl radical scavaging properties of 3-aminobenzamide and nicotinamide to 1,1-dimethyl urea

\begin{tabular}{ll}
$\begin{array}{l}\text { Scavenger } \\
(\mathrm{mmol} / \mathrm{l})\end{array}$ & $\begin{array}{l}\text { Decrease in formaldehyde } \\
\text { formation }(\%)\end{array}$ \\
\hline $\begin{array}{l}\text { 3-Aminobenzamide } \\
1\end{array}$ & $7 \pm 6$ \\
10 & $48 \pm 7^{\mathrm{a}}$ \\
50 & $76 \pm 7^{\mathrm{b}}$ \\
Nicotinamide & \\
1 & $10 \pm 7$ \\
10 & $21 \pm 12$ \\
50 & $86 \pm 8^{\mathrm{b}}$ \\
\hline
\end{tabular}

Values are mean \pm SEM of three separate experiments.

$\mathrm{a}, \mathrm{b}$ denote $p<0.05$ and $p<0.005$ respectively when tested against a constant $(0)$ using a one-sample t-test

\section{Effects of inhibitors of poly (ADP-ribose) synthetase on streptozotocin- and alloxan-induced B-cell injury}

Nicotinamide and 3-aminobenzamide diminished the toxic effects of STZ and alloxan in a dose-dependent fashion with saturation of this effect seen between 50 and $100 \mathrm{mmol} / 1$ (Fig. $3 \mathrm{a}$ and $3 \mathrm{~b}$ and Fig. $4 \mathrm{a}$ and $4 \mathrm{~b}$ ).

\section{Scavenging of the hydroxyl radical}

3-aminobenzamide and nicotinamide were tested competitively against the known hydroxyl radical scavenger, 1,1-dimethyl urea, for the ability to scavenge this radical. A decrease in the amount of formaldehyde produced by 1,1-dimethyl urea was indicative of hydroxyl

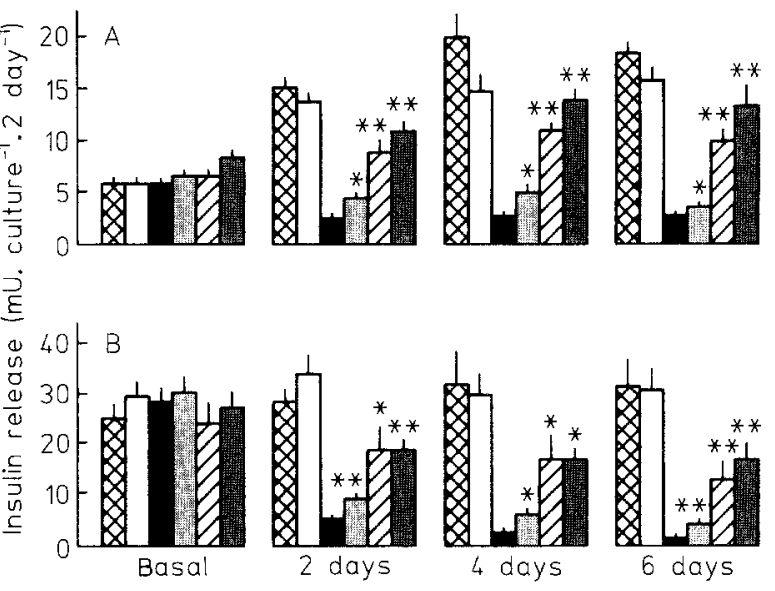

Fig. 3A and B. Insulin release after exposure to streptozotocin and various concentrations of 3-aminobenzamide (A) or nicotinamide (B) for $1 \mathrm{~h}$, with additions as follows: $\mathbf{A} \boldsymbol{\otimes}$ streptozotocin diluent only; $\square 100 \mathrm{mmol} / 1$ 3-aminobenzamide; $1 \mathrm{mmol} / 1$ streptozotocin; ․ $\quad 10 \mathrm{mmol} / 1 \quad 3$-aminobenzamide $+1 \mathrm{mmol} / 1$ streptozotocin; D $50 \mathrm{mmol} / 1$ 3-aminobenzamide $+1 \mathrm{mmol} / 1$ streptozotocin; 橉 $100 \mathrm{mmol} / 1$ 3-aminobenzamide $+1 \mathrm{mmol} / 1$ streptozotocin. B $\otimes$ streptozotocin diluent only; $\square 100 \mathrm{mmol} / 1$ nicotinamide; - $1 \mathrm{mmol} / 1 \mathrm{streptozotocin;} 10 \mathrm{mmol} / 1$ nicotinamide $+1 \mathrm{mmol} / 1$ streptozotocin; $50 \mathrm{mmol} / 1$ nicotinamide $+1 \mathrm{mmol} / 1$ streptozotocin; $100 \mathrm{mmol} / 1$ nicotinamide $+1 \mathrm{mmol} / 1$ streptozotocin. 'The expression of data and $p$ values are as described for Figures 1 and 2

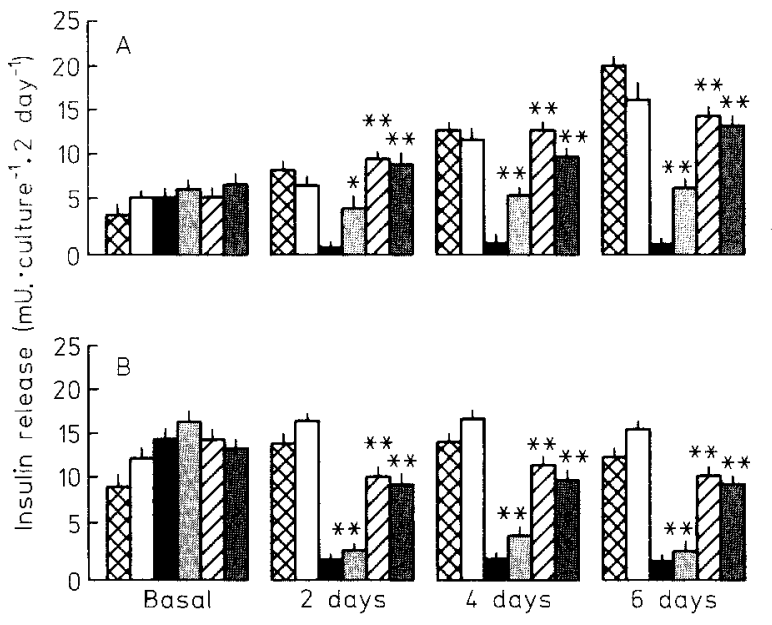

Fig.4 A and B. Insulin release after exposure to alloxan and various concentrations of 3-aminobenzamide (A) or nicotinamide (B) for $1 \mathrm{~h}$, with additions as follows: $\mathbf{A} \otimes$ alloxan diluent only; $\square 100 \mathrm{mmol} / \mathrm{l}$ 3-aminobenzamide; $2 \mathrm{mmol} / 1$ alloxan; $\square 10 \mathrm{mmol} / 1$ 3-aminobenzamide $+2 \mathrm{mmol} / \mathrm{l}$ alloxan; $50 \mathrm{mmol} / \mathrm{l}$ 3-aminobenzamide $+2 \mathrm{mmol} / 1$ alloxan; $100 \mathrm{mmol} / 1$-aminobenzamide $+2 \mathrm{mmol} / 1$ alloxan. $B \otimes$ alloxan diluent only; $\square 100 \mathrm{mmol} / 1$ nicotinamide; $2 \mathrm{mmol} / \mathrm{l}$ alloxan; $\square 10 \mathrm{mmol} / \mathrm{l}$ nicotinamide $+2 \mathrm{mmol} / 1$ alloxan; $50 \mathrm{mmol} / 1$ nicotinamide $+2 \mathrm{mmol} / 1 \mathrm{al}-$ loxan; $100 \mathrm{mmol} / 1$ nicotinamide $+2 \mathrm{mmol} / 1$ alloxan. The expression of data and $p$ values are as described in the previous figure legends

radical scavenging by the test compound. The results show that both 3 -aminobenzamide and nicotinamide scavenged the hydroxyl radical in a dose-dependent manner (Table 1). 
Table 2. Effect of 1,1-dimethyl urea, 3-aminobenzamide and nicotinamide on poly (ADP-ribose) synthetase activity

\begin{tabular}{cccc}
\hline $\begin{array}{l}\text { Inhibitor } \\
(\mathrm{mmol} / \mathrm{l})\end{array}$ & $\begin{array}{l}\text { Trichloracetic } \\
\text { acid-insoluble } \\
\text { proteins (cpm) }\end{array}$ & $\begin{array}{l}\text { Activity } \\
(\%)\end{array}$ & $\begin{array}{l}\text { Inhibition } \\
(\%)\end{array}$ \\
\hline 1,1-dimethyl urea & & & \\
0 & $989 \pm 39$ & 100 & 0 \\
$10^{-4}$ & $752 \pm 33^{\mathrm{a}}$ & 76 & 24 \\
$10^{-3}$ & $732 \pm 9^{\mathrm{b}}$ & 74 & 26 \\
$10^{-2}$ & $465 \pm 8^{\mathrm{b}}$ & 47 & 53 \\
$5 \times 10^{-2}$ & $376 \pm 8^{\mathrm{b}}$ & 38 & 62 \\
$10^{-1}$ & $208 \pm 5^{\mathrm{b}}$ & 21 & 79 \\
3 -Aminobenzamide & & & \\
0 & $1230 \pm 16$ & 100 & 0 \\
$10^{-4}$ & $873 \pm 59^{\mathrm{a}}$ & 71 & 29 \\
$10^{-3}$ & $480 \pm 8^{\mathrm{b}}$ & 39 & 61 \\
$10^{-2}$ & $123 \pm 4^{\mathrm{b}}$ & 10 & 90 \\
Nicotinamide & & & \\
0 & $1165 \pm 9$ & 100 & 0 \\
$10^{-4}$ & $790 \pm 7^{\mathrm{b}}$ & 68 & 32 \\
$10^{-3}$ & $430 \pm 6^{\mathrm{b}}$ & 37 & 63 \\
$10^{-2}$ & $125 \pm 14^{\mathrm{b}}$ & 11 & 89
\end{tabular}

$\mathrm{a}, \mathrm{b}$ denote $p<0.05$ and $p<0.005$ respectively when tested against cpm in the absence of inhibitor using a two-sample t-test

\section{Inhibition of poly (ADP-ribose) synthetase}

Nicotinamide, 3-aminobenzamide and 1,1-dimethyl urea were used for these studies. The results show that all three chemicals significantly inhibit poly (ADP-ribose) synthetase in a dose-dependent manner (Table 2). Nicotinamide and 3-aminobenzamide appear to be equally potent at inhibiting the enzyme, while 1,1-dimethyl urea is approximately tenfold less effective.

\section{Discussion}

The results of the present studies demonstrate that the hydroxyl radical scavenger, 1,1-dimethyl urea, is also an inhibitor of poly (ADP-ribose) synthetase and the poly (ADP-ribose) synthetase inhibitors, nicotinamide and 3-aminobenzamide, also are scavengers of the hydroxyl radical. All three of these chemicals have been shown to protect at least partially B cells against the toxic effects of STZ and alloxan. These findings may help provide new insights into the mechanisms of action of these two toxins. It has been proposed by Uchigata et al. [12] that alloxan and STZ induce B-cell damage by initiating biochemical events which cause DNA strand breaks. As part of the repair of these lesions nuclear poly (ADP-ribose) synthetase is activated to form poly (ADP-ribose) utilizing NAD as a substrate. This reaction leads to a critical depletion of NAD resulting in functional impairments and ultimately, cell death. In the case of alloxan, Uchigata and his coworkers hypothesized that alloxan exerts its initial effects through the generation of oxygen free radicals. This hypothesis is supported by the experiments reported here and elsewhere utilizing the superoxide scavenger, superoxide dismutase, and the hydroxyl scavenger, 1,1-dimethyl urea [3-7]. These scavengers effectively block the toxic effects of alloxan. Also, it has been shown that alloxan generates oxygen free radicals in the presence of islets [21]. While these results support the view that alloxan exerts its initial action through the generation of oxygen free radicals, the importance of DNA damage produced by these radicals has recently been brought into question by the studies of Sandler and Swenne [22]. In these experiments, alloxan did not induce detectable unscheduled DNA synthesis in mouse islets. These data suggest that the critical target for alloxan-induced damage is not nuclear DNA. The findings reported in this communication that 3-aminobenzamide and nicotinamide are scavengers of the hydroxyl radical would explain why these chemicals block alloxan-induced B-cell toxicity even in the absence of significant DNA damage. Additional experimentation is warranted to determine the critical target for alloxan-generated oxygen free radicals.

The finding that the hydroxyl radical scavenger, 1,1-dimethyl urea, partially protects B cells against the diabetogenic effects of STZ has generally been viewed as support for the hypothesis that STZ induces the generation of oxygen free radicals $[8,9]$. However, the results of the present studies argue against this mechanism and provide an alternative explanation for the action of 1,1-dimethyl urea. The data from the toxicity tests using 1,1-dimethyl urea, 3-aminobenzamide and nicotinamide show that a tenfold greater molar concentration of 1,1-dimethyl urea is required to diminish STZ-induced B-cell damage. In contrast with these results are those from experiments that compared the hydroxyl scavenging of nicotinamide and 3-aminobenzamide to 1,1-dimethyl urea. At equimolar concentrations $(10 \mathrm{mmol} / 1)$ approximately $50 \%$ of the hydroxyl radicals were scavenged by 3 -aminobenzamide and less than $50 \%$ by nicotinamide, indicating that these agents certainly are no more potent scavengers of the hydroxyl radical than 1,1-dimethyl urea. The experiments with the enzyme superoxide dismutase also do not support an oxygen radical mechanism. These studies are in agreement with those of others which have found that this enzyme does not protect against STZ-induced toxicity $[11,12]$. The recent report that STZ produces no detectable chemiluminescence when exposed to islets [21] provides further evidence that STZ does not act through the generation of oxygen free radicals. A possible explanation for the action of 1,1-dimethyl urea is provided by the studies that show that this chemical is an inhibitor of the enzyme poly (ADP-ribose) synthetase. However, when compared to the known inhibitors, 3-aminobenzamide and nicotinamide, it is over tenfold less effective at inhibiting this enzyme. This finding correlates with the results from the toxicity studies which show that 1,1-dimethyl urea is much less effective in blocking the toxic effects of STZ in B-cell monolayers. The data reported here are consistent with the viewpoint that 
STZ exerts its initial biochemical effects by the generation of highly reactive carbonium ions $\left(\mathrm{CH}_{3}{ }^{+}\right)$[23]. These ions are formed during the decomposition of methylnitrourea, which is the N-nitroso moiety of STZ. These carbonium ions are capable of alkylating DNA bases at various positions. As part of the process to repair these lesions the poly (ADP-ribose) system is activated and NAD is critically depleted. Why this necessary repair process is lethal in B cells remains to be determined.

Acknowledgements. The authors would like to thank R. Warren for typing the manuscript and W. Hill for graphic illustrations. This work was supported by NIH Grants ES03066, ES03113, AM20527, AM00595, and CA30547.

\section{References}

1. Rakieten N (1963) Studies on the diabetogenic action of streptozotocin (NSC-37917) Cancer Chemother Rep 29:91-103

2. Dulin WE, Soret MG (1978) Chemically and hormonally induced diabetes. In: Volk BW, Wellman KE (eds) The diabetic pancreas. Plenum Press, New York, pp 425-437

3. Heikkila RE, Cabbat FS (1978) Protection against alloxan-induced diabetes in mice by the hydroxyl radical scavenger dimethylurea. Eur J Pharmacol 52: 57-60

4. Tibaldi J, Benjamin J, Cabbat FS, Heikkila RE (1979) Protection against alloxan-induced diabetes by various urea derivatives: relationship between protective effects and reactivity with the hydroxyl radical. J Pharmacol Exptl Therap 211: 415-418

5. Grankvist K, Marklund S, Sehlin J, Taljedal I-B (1979) Superoxide dismutase, catalase and scavengers of hydroxyl radicals protect against the toxic action of alloxan on pancreatic islet cells in vitro. Biochem J 182: 17-25

6. Fischer LJ, Hamburger SA (1980) Inhibition of alloxan action in isolated pancreatic islets by superoxide dismutase, catalase and a metal chelator. Diabetes 29: 213-216

7. Fischer LJ, Hamburger SA (1980) Dimethylurea: a radical scavenger that protects isolated pancreatic islets from the effects of alloxan and dihydroxyfumerate exposure. Life Sci 26:1405-1409

8. Robbins MJ, Sharp RA, Slonim AE, Burr IM (1980) Protection against streptozotocin-induced diabetes by superoxide dismutase. Diabetologia 18: 55-58

9. Marklund S, Grankvist K (1980) Polyethyleneglycol superoxide dismutase (PEG-SOD) protects against streptozotocin-induced diabetes in mice. Acta Endocrinol 98 (Suppl 245): 43 (Abstract)

10. Sandler S, Andersson A (1982) The partial protective effect of the hydroxyl radical scavenger dimethyl urea on streptozotocin-induced diabetes in the mouse in vivo and in vitro. Diabetologia 23: 374-378
11. Gold G, Manning M, Heldt A, Nowlain R, Pettit JR, Grodsky GM (1981) Diabetes induced with multiple subdiabetogenic doses of streptozotocin. Lack of protection by exogenous superoxide dismutase. Diabetes 30:634-638

12. Uchigata Y, Yamamoto H, Kawamura A, Okamoto H (1982) Protection by superoxide dismutase, catalase and poly (ADP-ribose) synthetase inhibitors against alloxan- and streptozotocin-induced islet DNA strand breaks and against the inhibition of proinsulin synthesis. J Biol Chem 257: 6084-6088

13. Fischer LJ, Falany J, Fisher R (1983) Characteristics of nicotinamide and $\mathrm{N}^{1}$-methylnicotinamide protection from alloxan diabetes in mice. Toxicol Appl Pharmacol 70: 148-155

14. Chick WL, King DL, Lauris V (1977) Techniques for the preparation and maintenance of pancreatic beta cell monolayer cultures. In: Von Wasielewski E, Chick WL (eds) Pancreatic beta cell culture. Excerpta Medica, Amsterdam Oxford, pp 85-91

15. Wilson GL, Mossman BT, Craighead JE (1983) Use of pancreatic beta cells in culture to identify diabetogenic $\mathrm{N}$-nitroso compounds. In Vitro 19: 25-30

16. Wright P, Makulu DR, Vichick D, Susman KE (1971) Insulin immunoassay by back-titration: some characteristics of the technique and the insulin precipitant action of alcohol. Diabetes 20: 33-34

17. Klein SM, Cohen G, Cederbaum AI (1980) The interaction of hydroxyl radicals with dimethylsulfoxide produces formaldehyde. FEBS Lett 116: 220-222

18. McCord JM, Day ED, Jr (1978) Superoxide-dependent production of hydroxyl radical catalyzed by iron-EDTA complex. FEBS Lett 86: 139-142

19. Steffer C, Netter KJ (1979) On the mechanism of paraquat action on microsomal oxygen reduction and its relation to lipid peroxidation. Toxicol Appl Pharmacol 47: 593-601

20. Benjamin RC, Gill DM (1980) ADP-ribosylation in mammalian cell ghosts. J Biol Chem 255: 10493-10501

21. Asayama K, English D, Slonim AE, Burr IM (1984) Chemiluminescence as an index of drug-induced free radical production in pancreatic islets. Diabetes 33: 160-163

22. Sandler S, Swenne I (1983) Streptozotocin, but not alloxan, induces DNA repair synthesis in mouse pancreatic islets in vitro. Diabetologia 25: 444-447

23. Margison GP, O'Conner PJ (1979) Nucleic acid modification by $\mathrm{N}$-nitroso compounds. In: Grover PL (ed) Chemical carcinogens and DNA. CRC Press, Boca Raton, Florida, pp 111-160

Received: 12 December 1983

and in revised form: 20 August 1984

Dr. G. L. Wilson

Department of Anatomy

University of South Alabama

College of Medicine

Mobile

Alabama 36688

USA 